\title{
The relationship between polyphenols and miRNAs: a novel therapeutic strategy for metabolic associated fatty liver disease
}

Hatice Merve Bayram ${ }^{1}$, 0000-0002-7073-2907

Fatih Eren ${ }^{2}, 0000-0001-8126-2413$

Fatma Esra Güneș ${ }^{3}, 0000-0003-0334-7598$

\author{
${ }^{1}$ Department of Nutrition and Dietetics, Faculty of Health Sciences, Istanbul Gelisim \\ University, Istanbul, Turkey \\ ${ }^{2}$ Institute of Gastroenterology, Marmara University, Istanbul, Turkey \\ ${ }^{3}$ Department of Nutrition and Dietetics, Faculty of Health Sciences, Marmara University, \\ Istanbul, Turkey
}

Corresponding author: Fatih EREN

Institute of Gastroenterology, Marmara University, Istanbul, Turkey

E-mail: fatiheren@marmara.edu.tr

Phone: +902167775868

Fax Number: +902167775851

\begin{abstract}
Metabolic-associated fatty liver disease (MAFLD) is and is an increasingly recognized public health problem, affecting up to a quarter of the world's adult population. Although biopsy is the gold standard in the diagnosis of MAFLD, it can cause serious complications. Non-invasive methods cannot determine the stage and the subtypes of MAFLD. Additionally, the development and prognosis of MAFLD are modulated by epigenetic factors, in particular, microRNAs (miRNAs), be potential biomarkers for MAFLD. Polyphenols, which are found abundantly in fruits and vegetables, could alter gene expression with epigenetic factors such as miRNAs. This review aimed to present an overview of the relationship between polyphenols and miRNAs in MAFLD. According to the literature, miRNAs can be used as a diagnostic method for MAFLD, especially miRNA-122 and miRNA-34a. Although it has been shown that polyphenols may contribute to improving MAFLD, no study has shown the relationship between polyphenols and miRNAs in MAFLD. Therefore, it was not possible to determine the exact mechanisms of polyphenols on miRNAs in MAFLD. Future studies may be a source of hope for diet therapy for MAFLD patients and by developing polyphenols-related foods or drugs that target miRNAs which altering in MAFLD in the pharmaceutical and food industry.
\end{abstract}


Keywords: Polyphenols; metabolic associated fatty liver disease; microRNA

\section{Introduction}

Metabolic (dysfunction)-associated fatty liver disease (MAFLD), as with the previous term non-alcoholic fatty liver disease (NAFLD), is the most common chronic liver disorder worldwide, affecting more than one-third of the general population (around 30\% of adults in industrialized countries). ${ }^{[1,2]}$ The high prevalence of MAFLD has been associated with the increasing levels of unhealthy diets and low physical activity. ${ }^{[3]}$ MAFLD is a multisystem disorder and its pathophysiology is complex. ${ }^{[1]}$ It is recognized as the liver disease component of metabolic syndrome, which is mainly related to insulin resistance and genetic susceptibility. As the epidemics of obesity, type II diabetes mellitus, insulin resistance, and dyslipidemia increase day by day, the risk of MAFLD is increasing proportionately. ${ }^{[2,4]}$

In recent years, it has been shown that epigenetic factors, such as microRNAs (miRNA), may cause the development of a wide range of diseases including MAFLD. ${ }^{[5]}$ Therefore, miRNAs can be used in different clinical settings such as early diagnosis, monitoring progression, and response to treatment in various diseases. ${ }^{[6]}$ Almost all genetic pathways, including transcription factors, secreted factors, receptors, and transporters, can be modulated by miRNAs. ${ }^{[7]}$ Also, environmental conditions such as stress and nutritional status can modulate epigenetic factors thereby, they may be associated with diet and be useful for determining the effects of diet. ${ }^{[8]}$

Polyphenols have been popular that are known as functional foods, due to their biological activities including antioxidant, anti-inflammatory, anti-tumor, ameliorating lipid, carbohydrate, and amino acid metabolism, inhibiting platelet aggregation, and improving endothelin function. ${ }^{[9,10]}$ Regular consumption of polyphenols has been related to a reduction in the risk of several metabolic diseases, such as obesity, insulin resistance, hypertension, and cardiovascular diseases. ${ }^{[11-13]}$ Additionally, polyphenols may alter gene expression with epigenetic factors such as miRNAs by contributing to the modulation of key proteins. ${ }^{[14,15]}$ Thus, they contribute to the amelioration of MAFLD, as in many diseases, and may have modulated altering miRNAs in MAFLD, but the potential mechanisms of polyphenols and miRNAs in MAFLD are very limited. This review aimed to present an overview of the relationship between polyphenols and miRNAs in MAFLD with current approaches. 


\section{Materials and Methods}

Electronic searches were carried out using Scopus, Sciencedirect, and PubMed databases, to identify relevant studies about this subject. Keywords included in this review: "Phenolic" OR "Polyphenol” AND "Non-Alcoholic Fatty Liver Disease" OR "Metabolic dysfunction-associated fatty liver disease" AND "miRNA" OR "microRNAs". Theses, editorials, communications, and conference abstracts were excluded. The inclusion criteria were in vitro, in vivo or human clinical studies reporting the effects of polyphenols on MAFLD-associated miRNAs. We did not found any human clinical studies reporting the effects of polyphenols on MAFLD-associated miRNAs. Therefore, we included studies on varying miRNA levels in humans with MAFLD. Total 87 studies were included in this review.

\section{The Role and Expression Level of miRNAs in MAFLD}

miRNAs are endogenous, small non-coding RNAs that play a central role in regulating both mRNAs and protein expression of target genes. ${ }^{[16]}$ miRNAs are specific regulators that affect the stability or translation of the targeted mRNA. miRNAs are found abundantly in the liver and modulate a various spectrum of cellular processes related to inflammation, proliferation, differentiation, cellular growth, tissue remodeling. ${ }^{[17,18]}$ Therefore, miRNAs are potential biomarkers for many liver diseases due to their stability and can determine in tissue and serum. ${ }^{[19]}$

Today, thousands of miRNAs have been identified and their exact mechanisms are still unknown. Several different miRNAs were shown to be anomalously expressed in MAFLD (Figure 1). Several different miRNAs were shown to be anomalously expressed in MAFLD. A study showed that 44 miRNAs are abnormally expressed in MAFLD patients. ${ }^{[20]}$ It was found that serum levels of miRNA-122, miRNA-34a, and miRNA-16 are upregulated in MAFLD patients compared to control groups, and miRNA-122 and miRNA-34a are related to the severity of MAFLD. ${ }^{[21]}$ According to a study, serum levels of miRNA-21, miRNA-34a, miRNA-122, and miRNA-451 were upregulated in MAFLD patients and serum level of miRNA-122 was positively associated with steatosis severity. ${ }^{[22]}$ Another study noted that hsa-miRNA-122-5p, hsa-miRNA-1290, hsa-miRNA27b-3p and hsa-miRNA-192-5p were higher in MAFLD patients and compared to alanine transaminase (ALT) and fibrosis-4 index (FIB-4), miRNA levels were a more specific biomarker for MAFLD. ${ }^{[23]}$ A study investigated serum levels of miRNA-197, miRNA- 
146b, miRNA-10b, miRNA-181d, miRNA-34a, miRNA-122, miRNA-99a, and miRNA29a in MAFLD patients and found that serum levels of miRNA-181d, miRNA-99a, miRNA-197, and miRNA-146b were downregulated in MAFLD patients. Additionally, miRNA-197 and miRNA-10b were related to the severity of inflammation while miRNA181d and miRNA- 99a were related to serum levels of gamma-glutamyltransferase in nonalcoholic steatohepatitis (NASH) patients. ${ }^{[24]}$ The serum level of miRNA-122 in mild steatosis patients was lower compared to severe steatosis patients while the serum level of miRNA-122 in mild fibrosis patients was higher compared to severe fibrosis patients was observed. ${ }^{[25]}$ A study analyzed 84 miRNAs in MAFLD patients and showed that serum levels of miRNA-122, miRNA-192, miRNA-375, and miRNA-122 were upregulated in steatosis patients and serum levels of miRNA-122 and miRNA-192 were significantly downregulated in NASH patients compared to controls and steatosis patients. ${ }^{[6]}$ It was confirmed that the serum level of miRNA-21 is lower in NASH patients and serum levels of miRNA-122 and miRNA-192 are varied in MAFLD and NASH patients. ${ }^{[26]}$ Similarly, the serum level of miRNA-21 was lower in MAFLD patients was exhibited. ${ }^{[27]}$ miRNA122, miRNA-192, and miRNA-34a levels were associated with steatosis and inflammatory activity, only miRNA-16 levels were significantly correlated with fibrosis. The serum level of miRNA-34a was lower in NASH patients than in MAFLD patients. ${ }^{[28]}$ It was indicated that serum levels of miRNA-122 and miRNA-34a are higher, whereas miRNA331-3p and miRNA-30c are lower in MAFLD patients. ${ }^{[29]}$ The serum levels of miRNA122 and miRNA-34a were upregulated in MAFLD patients and strongly related to verylow-density lipoprotein (VLDL) and triglyceride (TG) levels were found. ${ }^{[30]}$ A study confirmed that the serum level of miRNA-122 is upregulated in MAFLD patients. ${ }^{[31]}$ It was revealed that expression of miRNA-122 is reduced in the morbidly obese group compared to moderately obese patients and the miRNA-122 level was increased in morbid obese with NASH patients than morbid obese with simple steatosis. Also, miRNA-33b expression was increased in NASH. ${ }^{[32]}$ Another study stated that serum levels of miRNA301 and miRNA-34a-5p are upregulated and miRNA-375 is downregulated in MAFLD patients. Especially miRNA-301a and miRNA-375 were increased in hepatocellular carcinoma patients. $^{[33]}$ A study found that 14 miRNAs are associated with MAFLD and the liver levels of miRNA-139-5p, miRNA-30b-5p, miRNA-122-5p, and miRNA-422a are lower and miRNA-146b-5p is higher in obese patients with MAFLD compared to the control group. ${ }^{[34]}$ It was showed that miRNA-22,miRNA-29a, and miRNA-663a are 
upregulated in MAFLD patients. ${ }^{[35]}$ Similarly, the other study noted that miRNA-34a, miRNA-192, miRNA-27b, miRNA-122, miRNA-22, miRNA-21, miRNA-197, miRNA30c, and miRNA-16 are correlated with MAFLD severity. ${ }^{[36]}$ Table 1 shows the studies about altering levels of miRNAs and Table 2 summarizes possible pathways of miRNAs in MAFLD patients.

\section{The Relationship Between Polyphenols and miRNAs}

Polyphenols are described as secondary metabolites that are found abundantly especially in fruits and vegetables as well as coffee, tea, red wine, and dark chocolate. ${ }^{[14,37,38]}$ Polyphenols consist of two main groups: flavonoids and non-flavonoids. Non-flavonoids include two sub-groups that phenolic acids and stilbenes. The main subgroups of flavonoids are flavanols, flavan-3-ols, isoflavones, and anthocyanidins whereas minor flavonoids are flavan-3,4-diols, dihydroflavonols, chalcones, dihydrochalcones, coumarins, and aurones. ${ }^{[37]}$ It is estimated that dietary intake of polyphenols is $1-1.2 \mathrm{~g}$ per day, and $40 \%$ of them consist of flavonoids. ${ }^{[9]} 5-10 \%$ of the polyphenols taken into the body are absorbed from the small intestine and after absorption, their conjugated forms go to the small intestine or liver. The non-absorbable part passes to the colon and is metabolized by the intestinal microbiota. ${ }^{[14]}$

Polyphenols have been shown to have various therapeutic effects such as anti-oxidant, anti-inflammatory, anti-diabetic, anti-allergic, anti-microbial, anti-cancer, and ameliorated lipid metabolism. ${ }^{[39]}$ Also, most of the therapeutic effects of polyphenols have been linked to altering gene expression encoding essential metabolic proteins. These gene modifications may result from the interaction of polyphenols with epigenetic factors such as signal cascades and/or miRNAs. ${ }^{[18]}$ Modulation of miRNAs of polyphenols appears to be a new strategy to regulate metabolism and related diseases; ${ }^{[40]}$ however, which mechanisms are included in this strategy are not yet known. ${ }^{[9,14]}$ In recent years, the beneficial effects of polyphenols in MAFLD patients have begun to attract attention and it has been shown that polyphenols may contribute to the amelioration of MAFLD due to their therapeutic effects. ${ }^{[41]}$ Although the effects of polyphenols on miRNAs have been known, possible pathways are not known. Also, there is no study evaluating the relationship between polyphenols and miRNAs in MAFLD. Due to this reason, we focused on the relationship between polyphenols and miRNAs which are altering the liver diseases and diseases that are caused by MAFLD (Figure 2). 


\section{i. In vitro studies}

Polyphenols have been shown to improve lipid metabolism, inhibit adipogenesis and inflammation and also exhibit antioxidant effects in cell line studies. Therefore, it is thought that polyphenols may contribute to the amelioration of MAFLD patients via miRNAs.

A study reported that miRNA-122 and miRNA-33 levels decrease in hepatic cells as a result of 5 hours $25 \mathrm{mg} / \mathrm{L}$ grape proanthocyanin treatment to mouse hepatoma cell lines (FAOs). ${ }^{[42]}$ The doses of $3.125,6.25,12.5,25$, and $50 \mathrm{~g} / \mathrm{mL}$ of ellagitannin treatment for human hepG2 cells for 72 hours, depending on the dose and time, hsa-let-7e, hsa-miR370, hsa-mir-373, and hsa -miR-526b upregulated whereas hsa-let-7a, hsa-let-7c, and hsalet-7d downregulated, thereby ellagitannin showed an antiproliferative effect in human hepG2 cells. ${ }^{[43]}$ In another study, HepG2 cells were treated with $50 \mathrm{mg} / \mathrm{L}$ of pure epigallocatechin gallate isolated from green tea (EGCG), $100 \mathrm{mg} / \mathrm{L}$ of grape seed proanthocyanin extract (GSPE) or $100 \mathrm{mg} / \mathrm{L}$ of cocoa proanthocyanidin extract (CPE). After $5 \mathrm{~h}$ treatment, miRNA-30b was downregulated by all three treatments, and EGCG or CPE treatments upregulated miRNA-1224-3p, miRNA-197, and miRNA-532-3p levels. ${ }^{[15]}$ The administration doses of $0.1,0.2,2$ and $20 \mathrm{~g} / \mathrm{mL}$ of EGCG treatment in hepG2 cells showed that miRNA-221, miRNA-181a, and miRNA-10b are upregulated according to dose-dependent. Therefore, EGCG inhibited osteopontin-dependent injury and fibrosis. ${ }^{[44]}$ It is known that obesity and dyslipidemia negatively affect the development of MAFLD. ${ }^{[4]}$ Studies have shown that the treatment of preadipocyte cells with polyphenols improved the altering of miRNAs levels. For example; administration dose of $25 \mathrm{M}$ of transresveratrol (RSV), trans-resveratrol-3-O-sulfate (3S), trans-resveratrol-3'-O-glucuronide $(3 \mathrm{G})$ or trans-resveratrol-4'-O-glucuronide $(4 \mathrm{G})$ treatment in 3T3-L1 maturing preadipocytes during differentiation for 8 days; after treatments of $3 \mathrm{G}$ and $4 \mathrm{G}$ cause inhibition in adipogenesis by upregulation of miRNA-155..$^{[45]}$ A study confirmed that miRNA-17-5p is upregulated in 3T3-L1 matured pre-adipocyte cells with $25 \mathrm{M}$ of curcumin treatment. Additionally, miRNA-17-5p was found to target levels of the tcf7L2 gene so reducing the risk of diabetes and show an inhibitor effect on adipogenesis. ${ }^{[46]}$ Human pre-adipocyte cells treated with $25 \mathrm{~mol} / \mathrm{L}$ of the extra-virgin olive oil polyphenols for $6 \mathrm{~h}$ resulted in upregulation in intracellular let-7c and downregulation in miRNA-155 and miRNA-34a levels and these results inversely correlated with the degree of inflammation. Accordingly, miRNA-155-5p, miRNA-34a-5p, and let-7c-5p associated 
with the nuclear factor kappa (NF- B) pathway were inversely modulated by TNF- in both cells and exosomes. These conditions have had a significant effect on reducing obesity-related inflammation. ${ }^{[47]}$

\section{ii. In vivo studies}

The development of MAFLD is characterized by degenerative antioxidant balance and progressive inflammation, which is impaired by the accumulation of fatty acids in the liver. Additionally, the prevalence of MAFLD increases rapidly and is in parallel with obesity, which often leads to comorbidity metabolic diseases. The prevalence of MAFLD is approximately $75 \%$ in obese patients and this rate can increase up to $90 \%$ in morbidly obese patients. ${ }^{[48]}$ No in vivo studies investigated the relationship between polyphenols and miRNAs in MAFLD. We exhibited the relationship between polyphenols and miRNAs in obese mice or rat models fed with a high-fat diet due to the significant correlation between obesity and MAFLD.

A study demonstrated that miRNA-122 and miRNA-125b are upregulated with $2 \mathrm{mg} / \mathrm{g}$ of quercetin treatment after 6 weeks compared to $0.2 \mathrm{mg} / \mathrm{g}$ of quercetin treatment in female mice ${ }^{[49]}$ Mice were fed either a control diet, a high-fat diet, or a high-fat diet treated with 0.5 to $1.0 \%$ coffee polyphenols (CPP) for 15 weeks and the treatment of CPP led to an increase in miRNA-122 levels. Additionally, mRNA levels of sterol regulatory elementbinding protein (SREBP)-1c, acetyl-CoA carboxylase-1 and -2, stearoyl-CoA desaturase1 , and pyruvate dehydrogenase kinase- 4 in the liver were strongly decreased in mice fed with CPP ${ }^{[50]}$ In another study, mice were fed a control or a high-fat diet and treated with a high dose of quercetin for 10 weeks. miRNA-103, miRNA-107 ve miRNA-122 levels were reduced after treatment. The study suggested that polyphenols were able to prevent and/or weaken the metabolic effects of high-fat and high-cholesterol diets when administered in continuous doses and indicating the importance of dietary intervention in the treatment of MAFLD. ${ }^{[51]}$

Rats were fed lard oil diets or lard oil with $250 \mathrm{mg} / \mathrm{kg}$ of grape seed proanthocyanin extracts (GSPE) for 3 weeks and after treatment miRNA-122 and miRNA-33 were downregulated. These results suggested that proanthocyanidin treatment increased hepatic cholesterol efflux to produce new high-density lipoprotein (HDL) particles by inhibiting miRNA-33, and it decreased lipogenesis by inhibiting miRNA-122. ${ }^{[42]}$ A study reported that $500 \mathrm{mg} / \mathrm{kg}$ of green tea treatment for 12 weeks cause upregulation of miRNA-335 levels in adipose tissue in mice fed a high-fat diet. Also, miRNA-335 turned 
downregulated genes involved in insulin signaling and lipid metabolism and green tea inhibited TNF- levels. ${ }^{[52]}$ The upregulation of miR-221 was observed after 16 weeks with green tea treatment $(20 \mathrm{mg} / \mathrm{kg})$ treatment in rats with thioacetamide (TAA)-induced hepatic fibrosis. The treatment with EGCG blocked the effects of TAA and inhibited osteopontin-dependent injury and fibrosis. ${ }^{[44]}$ According to another study, mice were fed a high-fat diet or high-fat diet with curcumin ( $2 \mathrm{M}$ dose for 6 days and $10 \mathrm{M}$ for only the 7th day), and upregulated miRNA-17-5p inhibited adipogenesis and decreased diabetes risk by suppressing Wnt signal pathway effector Tcf712 gene after treatment. ${ }^{[46]}$

It was observed that treatment with $30 \mathrm{mg} / \mathrm{kg}$ of resveratrol for 8 weeks, fatty acid synthase and SREBP1 protein levels decreased, carnitine palmitoyltransferase-1a levels increased in obese rats. Fatty acid synthase reduced after miRNA-103-3p, miRNA-107-3p, and miRNA-122-5p transfection; carnitine palmitoyl transferase-1 downregulated after over-expression of miRNA-107-3p. The study showed that the targetted genes are SREBF1 for miRNA-103-3p and miRNA-107-3p; FASN for miRNA-122-5p and CPT1 for miRNA-107-3p. ${ }^{[53]}$ In a study, mice or apoE ${ }^{-/}$mice were fed with $0.006 \%$ of quercetin, hesperidin, naringenin, anthocyanin, catechin, curcumin, proanthocyanin, caffeic acid, or ferulic acid or a control diet for 8 weeks. Mmu-miRNA-291b-5p and mmu-miRNA-296-5p were upregulated while mmu-miRNA-30c-1, mmu-miRNA-467b and mmu-miRNA-374 were downregulated after 8 weeks. ${ }^{[54]}$ The effects of polyphenols on miRNAs as reported by various studies are given in Table 3.

\section{Discussion}

The prevalence of MAFLD is not known accurately, but it is increasing rapidly and in parallel with diseases such as diabetes, dyslipidemia, and especially obesity. It is thought that the prevalence, which is $75 \%$ in obese patients, can increase up to $90 \%$ in morbidly obese patients. ${ }^{[48]}$ Today, obesity is a pandemic, more than 1.9 billion adults are overweight and 600 billion adults are obese. ${ }^{[55]}$ It also plays a key role in the development of MAFLD in genetic predisposition as well as in the environment with dietary habits. ${ }^{[56]}$ Many invasive and non-invasive methods are used in the diagnosis of MAFLD. Although biopsy, which is used as an invasive method and gold standard, has many disadvantages due to its serious complications such as severe pain, bleeding, infection, and death in some cases hence it is difficult to practice in the clinic. ${ }^{[57,58]}$ Non-invasive methods, liver enzyme tests, ultrasound, and other imaging methods are widely used, but these are 
insufficient to define the stage and the subtypes of MAFLD. ${ }^{[57]}$ Therefore, there is an increasing demand to identify new and reliable biomarkers. This review showed that miRNAs can be used to diagnose MAFLD and its subtypes. ${ }^{[8,20-35]}$

miRNAs, which are potential biomarkers for the diagnosis of MAFLD, are stable and can be detected in plasma, serum, and other biological fluids. ${ }^{[19]}$ Studies have shown that miRNAs can be used to diagnose the stages and the subtypes of MAFLD. ${ }^{[8,20-35]}$ It has been shown in most studies that the serum levels of miRNA-122 are particularly high in MAFLD patients. ${ }^{[6,21-25,28,35,59]}$ Additionally, miRNA-34a is upregulated in patients with NASH and a reliable biomarker in distinguishing MAFLD and NASH. ${ }^{[20,21,27-29]}$ Moreover, the pathways of miRNAs that are thought to have a relationship in the diagnosis and prognosis of MAFLD are shown in Table 2, but further studies are needed to confirm their pathways and whether miRNAs can be used accurately in the diagnosis of MAFLD.

Additionally, there is no pharmacological treatment for MAFLD, and only lifestyle modification with diet therapy and physical activity is recommended for these patients. ${ }^{[60]}$ Fruits and vegetables are the basis of a healthy diet, and are also, rich in polyphenols. ${ }^{[37]}$ It has been linked to altering gene expression encoding essential metabolic proteins that polyphenols positively affect health. These gene modifications can be caused by the interaction of polyphenols with epigenetic factors such as signal cascades and/or miRNAs; ${ }^{[18]}$ but its exact mechanisms are still unknown. ${ }^{[9,14]}$ It has been shown that polyphenols can contribute to improving MAFLD, but no study has shown the relationship between polyphenols and miRNAs in MAFLD. Also, studies in obese, high-fat diet-fed mice and rats models, and in vitro studies linked to liver and pre-adipocyte cell lines have shown that polyphenols can modulate the altering miRNAs profiles in liver diseases, particularly MAFLD, but the studies and polyphenol groups are limited. ${ }^{[13,41-53]}$ Moreover, there is no clinical study has been found. In vitro, in vivo and clinical studies are to be performed to demonstrate and explain the relationship between polyphenols and miRNAs for MAFLD patients is quite essential.

\section{Conclusion}

The role of miRNAs in the diagnosis and prognosis of MAFLD is an inescapable fact, and they can be an easy and practical non-invasive method in the diagnosis of MAFLD. Although polyphenols have been shown to contribute to the amelioration of MAFLD, as 
in many diseases, and may have modulated altering miRNAs in MAFLD, due to their antioxidant, anti-inflammatory, anti-diabetic, anti-cancer, and improving lipid metabolism. From the current studies, it was not possible to determine the exact effects of polyphenols on miRNAs in MAFLD. Future studies may be a source of hope for diet therapy for MAFLD patients and by developing polyphenols-related foods or drugs that target miRNAs which altering in MAFLD in the pharmaceutical and food industry.

\section{References}

1. Eslam M, Sanyal AJ, George J. MAFLD: a consensus-driven proposed nomenclature for metabolic associated fatty liver disease. Gastroenterology 2020;158(7):1999-2014.

2. Kawano Y, Cohen DE. Mechanisms of hepatic triglyceride accumulation in nonalcoholic fatty liver disease. J Gastroenterol 2013;48(49):434-441.

3. Eslam M, Newsome PN, Sarin SK, Anstee QM, Targher G, Romero-Gomez M, et al. A new definition for metabolic dysfunction-associated fatty liver disease: An international expert consensus statement. J Hepatol 2020;73(1)202-209.

4. Cohen JC, Horton JD, Hobbs HH. Human fatty liver disease: Old questions and new insights. Science 2011;332(6037):1519-1523.

5. Gerhard GS, DiStefano JK. Micro RNAs in the development of non-alcoholic fatty liver disease. World J Hepatol 2015;7(2):226-234.

6. Pirola CJ, Gianotti TF, Castaño GO, Mallardi P, Martino JS, Ledesma MMG, et al. Circulating microRNA signature in non-alcoholic fatty liver disease: From serum noncoding RNAs to liver histology and disease pathogenesis. Gut 2015;64(5):800-812.

7. Esquela-Kerscher A, Slack FJ. Oncomirs - MicroRNAs with a role in cancer. Nat Rev Cancer 2006;6:259-269.

8. Rome S. Use of miRNAs in biofluids as biomarkers in dietary and lifestyle intervention studies. Genes Nutr 2015;10(5):33.

9. Milenkovic D, Jude B, Morand C. miRNA as molecular target of polyphenols underlying their biological effects. Free Radic Biol Med 2013;64:40-51.

10. Septembre-Malaterre A, Le Sage F, Hatia S, Catan A, Janci L, Gonthier MP. Curcuma longa polyphenols improve insulin-mediated lipid accumulation and attenuate proinflammatory response of 3T3-L1 adipose cells during oxidative stress through regulation of key adipokines and antioxidant enzymes. BioFactors 2016;42(4):418-430.

11. Rodriguez A, Vauzour D, Krueger CG, Shanmuganayagam D, Reed J, Calani L, et 
al. Bioavailability, bioactivity and impact on health of dietary flavonoids and related compounds: an update. Arch Toxicol 2014;88(10):1803-1853.

12. Mazidi M, Kengne AP. Higher adherence to plant-based diets are associated with lower likelihood of fatty liver. Clin Nutr 2019;38(4):1672-1677.

13. Salomone F, Ivancovsky-Wajcman D, Fliss-Isakov N, Webb M, Grosso G, Godos $\mathrm{J}$, et al. Higher phenolic acid intake independently associates with lower prevalence of insulin resistance and non-alcoholic fatty liver disease. JHEP Reports 2020;2(2):100069.

14. Corrêa TAF, Rogero MM. Polyphenols regulating microRNAs and inflammation biomarkers in obesity. Nutrition 2019;59:150-157.

15. Arola-Arnal A, Bladé C. Proanthocyanidins Modulate MicroRNA Expression in Human HepG2 Cells. PLoS One 2011;6(10):e25982.

16. Ceccarelli S, Panera N, Gnani D, Nobili V. Dual role of microRNAs in NAFLD. Int J Mol Sci 2013;14(4):8437-8455.

17. Lakner AM, Bonkovsky HL, Schrum LW. microRNAs: Fad or future of liver disease. World J Gastroenterol 2011;17(20):2536-2542.

18. Bladé C, Baselga-Escudero L, Salvadó MJ, Arola-Arnal A. miRNAs, polyphenols, and chronic disease. Mol Nutr Food Res 2013;57(1):58-70.

19. Weber JA, Baxter DH, Zhang S, Huang DY, Huang KH, Lee MJ, et al. The microRNA spectrum in 12 body fluids. Clin Chem 2010; 56(11), 1733-1741.

20. Soronen J, Yki-Järvinen H, Zhou Y, Sädevirta S, Sarin AP, Leivonen M, et al. Novel hepatic microRNAs upregulated in human nonalcoholic fatty liver disease. Physiol Rep 2016;4(1):e12661.

21. Cermelli S, Ruggieri A, Marrero JA, Ioannou GN, Beretta L. Circulating microRNAs in patients with chronic hepatitis $\mathrm{C}$ and non-alcoholic fatty liver disease. PLoS One 2011;6(8):e23937.

22. Yamada H, Suzuki K, Ichino N, Ando Y, Sawada A, Osakabe K, et al. Associations between circulating microRNAs (miR-21, miR-34a, miR-122 and miR-451) and non-alcoholic fatty liver. Clin Chim Acta 2013;424:99-103.

23. Tan Y, Ge G, Pan T, Wen D, Gan J. A pilot study of serum micrornas panel as potential biomarkers for diagnosis of nonalcoholic fatty liver disease. PLoS One 2014;9(8):e105192.

24. Celikbilek M, Baskol M, Taheri S, Deniz K, Dogan S, Zararsiz G, et al. Circulating microRNAs in patients with non-alcoholic fatty liver disease. World J Hepatol 
2014;6(8):613-620.

25. Miyaaki H, Ichikawa T, Kamo Y, Taura N, Honda T, Shibata H, et al. Significance of serum and hepatic microRNA-122 levels in patients with non-alcoholic fatty liver disease. Liver Int 2014;34(7):e302-e307.

26. Becker PP, Rau M, Schmitt J, Malsch C, Hammer C, Bantel H, et al. Performance of serum microRNAs-122,-192 and-21 as biomarkers in patients with non-Alcoholic steatohepatitis. PLoS One 2015;10(11):e0142661.

27. Sun C, Huang F, Liu X, Xiao X, Yang M, Hu G, et al. miR-21 regulates triglyceride and cholesterol metabolism in non-alcoholic fatty liver disease by targeting HMGCR. Int J Mol Med 2015;35(3):847-853.

28. Liu XL, Pan Q, Zhang RN, Shen F, Yan SY, Sun C, et al. Disease-specific miR34a as diagnostic marker of nonalcoholic steatohepatitis in a Chinese population. World $\mathrm{J}$ Gastroenterol 2016;22(44):9844-9852.

29. Zarrinpar A, Gupta S, Maurya MR, Subramaniam S, Loomba R. Serum microRNAs explain discordance of non-alcoholic fatty liver disease in monozygotic and dizygotic twins: a prospective study. Physiol Behav 2016;65(9):1546-1554.

30. Salvoza NC, Klinzing DC, Gopez-Cervantes J, Baclig MO. Association of circulating serum MIR-34a and MIR-122 with dyslipidemia among patients with nonalcoholic fatty liver disease. PLoS One 2016;11(4):e0153497.

31. Akuta N, Kawamura Y, Suzuki F, Saitoh S, Arase Y, Kunimoto H, et al. Impact of circulating miR-122 for histological features and hepatocellular carcinoma of nonalcoholic fatty liver disease in Japan. Hepatol Int 2016;10(4):647-656.

32. Auguet T, Aragonès G, Berlanga A, Guiu-Jurado E, Martí A, Martínez S, et al. miR33a/miR33b* and miR122 as Possible Contributors to Hepatic Lipid Metabolism in Obese Women with Nonalcoholic Fatty Liver Disease. Int J Mol Sci 2016;17(10):1620.

33. Guo Y, Xiong Y, Sheng Q, Zhao S, Wattacheril J, Flynn CR. A micro-RNA expression signature for human NAFLD progression. J Gastroenterol 2016;51(10):10221030 .

34. Latorre J, Moreno-Navarrete JM, Mercader JM, Sabater M, Rovira Ò, Gironès J, et al. Decreased lipid metabolism but increased FA biosynthesis are coupled with changes in liver microRNAs in obese subjects with NAFLD. Int J Obes 2017;41(4):620-630.

35. López-Riera M, Conde I, Tolosa L, Zaragoza Á, Castell JV, Gómez-Lechón MJ, et al. New microRNA biomarkers for drug-induced steatosis and their potential to predict the 
contribution of drugs to non-alcoholic fatty liver disease. Front Pharmacol 2017;8:3.

36. López-Riera M, Conde I, Quintas G, Pedrola L, Zaragoza A, Perez-Rojas J, et al. Non-invasive prediction of NAFLD severity: A comprehensive, independent validation of previously postulated serum microRNA biomarkers. Sci Rep 2018;8:10606.

37. Szczepaniak OM, Kobus-Cisowska J, Kusek W, Przeor M. Functional properties of Cornelian cherry (Cornus mas L.): a comprehensive review. Eur Food Res Technol 2019;245:2071-2087.

38. Bayram HM, Ozturkcan SA. Bioactive components and biological properties of cornelian cherry (Cornus mas L.): A comprehensive review. J Func Food 2020;75:104252. 39. Sengul IY, Yucel E. Antimicrobial properties of wild fruits. Biol Divers Conserv 2015;8(1):69-77.

40. Bladé C, Baselga-Escudero L, Arola-Arnal A. microRNAs as new targets of dietary polyphenols. Curr Pharm Biotechnol 2014;15(4):343-351.

41. Rodriguez-Ramiro I, Vauzour D, Minihane AM. Polyphenols and non-alcoholic fatty liver disease: Impact and mechanisms. Proc Nutr Soc 2016;75(1):47-60.

42. Baselga-Escudero L, Bladé C, Ribas-Latre A, Casanova E, Salvadó MJ, Arola L, et al. Grape seed proanthocyanidins repress the hepatic lipid regulators miR-33 and miR-122 in rats. Mol Nutr Food Res 2012;56(11):1636-1646.

43. Wen XY, Wu SY, Li ZQ, Liu ZQ, Zhang JJ, Wang GF, et al. Ellagitannin (BJA3121), an anti-proliferative natural polyphenol compound, can regulate the expression of MiRNAs in HepG2 cancer cells. Phyther Res 2009;23(6):778-784.

44. Arffa ML, Zapf MA, Kothari AN, Chang V, Gupta GN, Ding X, et al. Epigallocatechin-3-gallate upregulates miR-221 to inhibit osteopontin-dependent hepatic fibrosis. PLoS One 2016;11(12):e0167435.

45. Eseberri I, Lasa A, Miranda J, Gracia A, Portillo MP. Potential miRNA involvement in the anti-adipogenic effect of resveratrol and its metabolites. PLoS One 2017;12(9):e0184875.

46. Tian L, Song Z, Shoa W, Du WW, Zhao LR, Zeng K, et al. Curcumin represses mouse 3T3-L1 cell adipogenic differentiation via inhibiting miR-17-5p and stimulating the Wnt signalling pathway effector Tcf712. Cell Death Dis 2017;8(1):e2559.

47. Carpi S, Scoditti E, Massaro M, Polini B, Manera C, Digiacomo M, et al. The extra-virgin olive oil polyphenols oleocanthal and oleacein counteract inflammationrelated gene and mirna expression in adipocytes by attenuating nf- $\mathrm{b}$ activation. Nutrients 
2019;11(2):2855.

48. Holterman AX, Guzman G, Fantuzzi G, Wang H, Aigner K, Browne A, et al. Nonalcoholic fatty liver disease in severely obese adolescent and adult patients. Obesity 2013;21(3):591-597.

49. Boesch-Saadatmandi C, Wagner AE, Wolffram S, Rimbach G. Effect of quercetin on inflammatory gene expression in mice liver in vivo - Role of redox factor 1, miRNA122 and miRNA-125b. Pharmacol Res 65(5), 523-530.

50. Murase T, Misawa K, Minegishi Y, Aoki M, Ominami H, Suzuki Y, et al. Coffee polyphenols suppress diet-induced body fat accumulation by downregulating SREBP-1c and related molecules in C57BL/6J mice. Am J Physiol-Endocrinol Metab 2011;300(1):E122-E133.

51. Joven J, Espinel E, Rull A, Aragonès G, Rodríguez-Gallego E, Camps J, et al. Plant-derived polyphenols regulate expression of miRNA paralogs miR-103/107 and miR122 and prevent diet-induced fatty liver disease in hyperlipidemic mice. Biochim Biophys Acta - Gen Subj 2012;1820(7):894-899.

52. Otton R, Bolin AP, Ferreira LT, Marinovic MP, Rocha ALS, Mori MA. Polyphenol-rich green tea extract improves adipose tissue metabolism by down-regulating miR-335 expression and mitigating insulin resistance and inflammation. J Nutr Biochem 2018;57:170-179.

53. Gracia A, Fernández-Quintela A, Miranda J, Eseberri I, González M, Portillo MP. Are miRNA-103, miRNA-107 and miRNA-122 involved in the prevention of liver steatosis induced by resveratrol? Nutrients 2017;9(4):360.

54. Milenkovic D, Deval C, Gouranton E, Landrier JF, Scalbert A, Morand C, et al. Modulation of miRNA expression by dietary polyphenols in apoE deficient mice: A new mechanism of the action of polyphenols. PLoS One 2012;7(1):e29837.

55. World Health Organization. [Internet]. Obesity and overweight; 2015 [cited 2021 Jan 12]. Available from: https:/www.who.int/news-room/fact-sheets/detail/obesity-andoverweight.

56. Festi D, Schiumerini R, Marzi L, Di Biase AR, Mandolesi D, Montrone L, et al. Review article: the diagnosis of non-alcoholic fatty liver disease -- availability and accuracy of non-invasive methods. Aliment Pharmacol Ther. 2013;37(4):392-400.

57. Liu Z, Wang Y, Borlak J, Tong W. Mechanistically linked serum miRNAs distinguish between drug induced and fatty liver disease of different grades. Sci Rep 
2016;6:23709.

58. Seeff LB, Everson GT, Morgan TR, Curto TM, Lee WM, Ghany MG, et al. Complication rate of percutaneous liver biopsies among persons with advanced chronic liver disease in the HALT-C trial. Clin Gastroenterol Hepatol 2010;8(10):877-883.

59. Akuta N, Kawamura Y, Suzuki F, Saitoh S, Arase Y, Fujiyama S, et al. Analysis of association between circulating miR-122 and histopathological features of nonalcoholic fatty liver disease in patients free of hepatocellular carcinoma. BMC Gastroenterol $2016 ; 16: 1414$.

60. Glass O, Filozof C, Noureddin M, Berner-Hansen M, Schabel E, Omokaro SO, Set al. Standardization of Diet and Exercise in Clinical Trials of NAFLD-NASH: Recommendations from the Liver Forum. J Hepatol 2020;73(3):680-693.

61. Su Q, Kumar V, Sud N, Mahato RI. MicroRNAs in the pathogenesis and treatment of progressive liver injury in NAFLD and liver fibrosis. Adv Drug Deliv Rev 2018;129:54-63.

62. Esau C, Davis S, Murray SF, Yu XX, Pandey SK, Pear M, et al. miR-122 regulation of lipid metabolism revealed by in vivo antisense targeting. Cell Metab 2006;3(29):87-98.

63. Elmén J, Lindow M, Schütz S, Lawrence M, Petri A, Obad S, et al. LNA-mediated microRNA silencing in non-human primates. Nature 2008;452(7189):896-899.

64. Hsu SH, Wang B, Kota J, Yu J, Costinean S, Kutay H, et al. Essential metabolic, anti-inflammatory, and anti-tumorigenic functions of miR-122 in liver. J Clin Invest 2012;122(8):2871-2883.

65. Zheng L, Lv GC, Sheng J, Yang YD. Effect of miRNA-10b in regulating cellular steatosis level by targeting PPAR- expression, a novel mechanism for the pathogenesis of NAFLD. J Gastroenterol Hepatol 2010;25(1):156-163.

66. Rayner KJ, Suárez Y, Dávalos A, Parathath S, Fitzgerald ML, Tamehiro N, et al. MiR-33 Contributes to the Regulation of Cholesterol Homeostasis. Science 2010;328(5985):1570-1573.

67. Dávalos A, Goedeke L, Smibert P, Ramírez CM, Warrier NP, Andreo U, et al. $\mathrm{miR}-33 \mathrm{a} / \mathrm{b}$ contribute to the regulation of fatty acid metabolism and insulin signaling. Proc Natl Acad Sci USA 2011;108(22):9232-9237.

68. Gerin I, Clerbaux LA, Haumont O, Lanthier N, Das AK, Burant CF, et al. Expression of miR-33 from an SREBP2 intron inhibits cholesterol export and fatty acid 
oxidation. J Biol Chem 2010;285(44):33652-33661.

69. Min HK, Kapoor A, Fuchs M, Mirshahi F, Zhou H, Maher J, et al. Increased hepatic synthesis and dysregulation of cholesterol metabolism is associated with the severity of nonalcoholic fatty liver disease. Cell Metab 2012;15(5):665-674.

70. Castro RE, Ferreira DM, Afonso MB, Borralho PM, Machado MV, Cortez-Pinto $\mathrm{H}$, et al. MiR-34a/SIRT1/p53 is suppressed by ursodeoxycholic acid in the rat liver and activated by disease severity in human non-alcoholic fatty liver disease. J Hepatol 2013;58(1):119-125.

71. Vilà L, Elias I, Roca C, Ribera A, Ferre T, Casellas A, et al. AAV8-mediated Sirt1 gene transfer to the liver prevents high carbohydrate diet-induced nonalcoholic fatty liver disease. Mol Ther-Methods Clin Dev 2014;1:4039.

72. Sacco J, Adeli K. MicroRNAs: Emerging Roles in Lipid and Lipoprotein Metabolism. Curr Opin Lipidol 2012;23(3):220-225.

73. Coll M, Taghdouini A, Perea L, Mannaerts I, Vila-Casadesús M, Blaya D, et al. Integrative miRNA and Gene Expression Profiling Analysis of Human Quiescent Hepatic Stellate Cells Sci Rep 2014;5:11549.

74. Iizuka M, Ogawa T, Enomoto M, Motoyama H, Yoshizato K, Ikeda K, et al. Induction of microRNA-214-5p in human and rodent liver fibrosis. Fibrogenes Tissue Repair 2012;5:12.

75. Ji J, Zhang J, Huang G, Qian J, Wang X, Mei S. Over-expressed microRNA-27a and $27 \mathrm{~b}$ influence fat accumulation and cell proliferation during rat hepatic stellate cell activation. FEBS Lett 2009;583(4):759-766.

76. $\mathrm{Ng} \mathrm{R}, \mathrm{Wu} \mathrm{H}$, Xiao $\mathrm{H}$, Chen $\mathrm{X}$, Willenbring $\mathrm{H}$, Steer $\mathrm{CJ}$, et al. Inhibition of microRNA-24 expression in liver prevents hepatic lipid accumulation and hyperlipidemia. Hepatology 2014;60(2):554-564.

77. Hur W, Lee JH, Kim SW, Kim JH, Bae SH, Kim M, et al. Downregulation of microRNA-451 in non-alcoholic steatohepatitis inhibits fatty acid-induced proinflammatory cytokine production through the AMPK/AKT pathway. Int J Biochem Cell Biol 2015;64:265-276.

78. de Conti A, Ortega JF, Tryndyak V, Dreval K, Moreno FS, Rusyn I, et al. MicroRNA deregulation in nonalcoholic steatohepatitisassociated liver carcinogenesis. Oncotarget 2017;8(51):88517-8828.

79. Liu XL, Cao HX, Wang BC, Xin FZ, Zhang RN, Zhou D, et al. miR-192-5p 
regulates lipid synthesis in non-Alcoholic fatty liver disease through SCD-1. World J Gastroenterol 2017;23(46):8140-8151.

80. Trajkovski M, Hausser J, Soutschek J, Bhat B, Akin A, Zavolan M, et al. MicroRNAs 103 and 107 regulate insulin sensitivity. Nature 2011;474:649-653.

81. Xu Q, Li Y, Shang YF, Wang HL, Yao MX. MiRNA-103: Molecular link between insulin resistance and nonalcoholic fatty liver disease. World $\mathrm{J}$ Gastroenterol 2015;21(2):511-516.

82. Blaya D, Aguilar-Bravo B, Hao F, Casacuberta-Serra S, Coll M, Perea L, et al. Expression of microRNA-155 in inflammatory cells modulates liver injury. Hepatology 2018;68(2):691-706.

83. Wang L, Zhang N, Wang Z, Ai D, Cao Z, Pan H. Decreased MiR-155 Level in the Peripheral Blood of Non-Alcoholic Fatty Liver Disease Patients may Serve as a Biomarker and may Influence LXR Activity. Cell Physiol Biochem 2016;39(6):2239_ 2248.

84. Ahn J, Lee $\mathrm{H}$, Chung $\mathrm{CH}$, Ha $\mathrm{T}$. High fat diet induced downregulation of microRNA-467b increased lipoprotein lipase in hepatic steatosis. Biochem Biophys Res Commun 2011;414(4):664-669.

85. Lynn FC. Meta-regulation: microRNA regulation of glucose and lipid metabolism. Trends Endocrinol Metab 2009;20(9):452-459. 


\section{Tables}

Table 1. miRNAs analysis in MAFLD patients

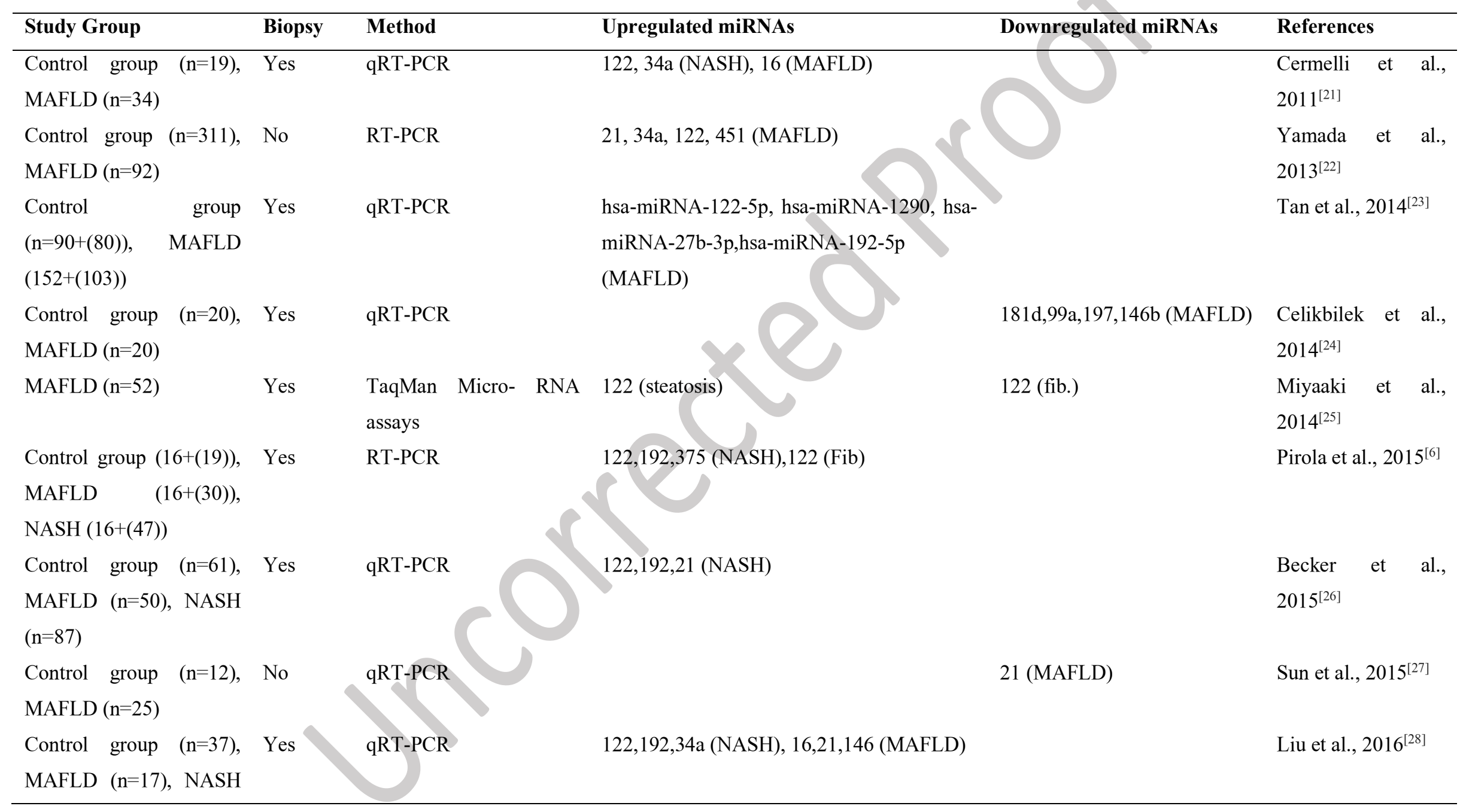




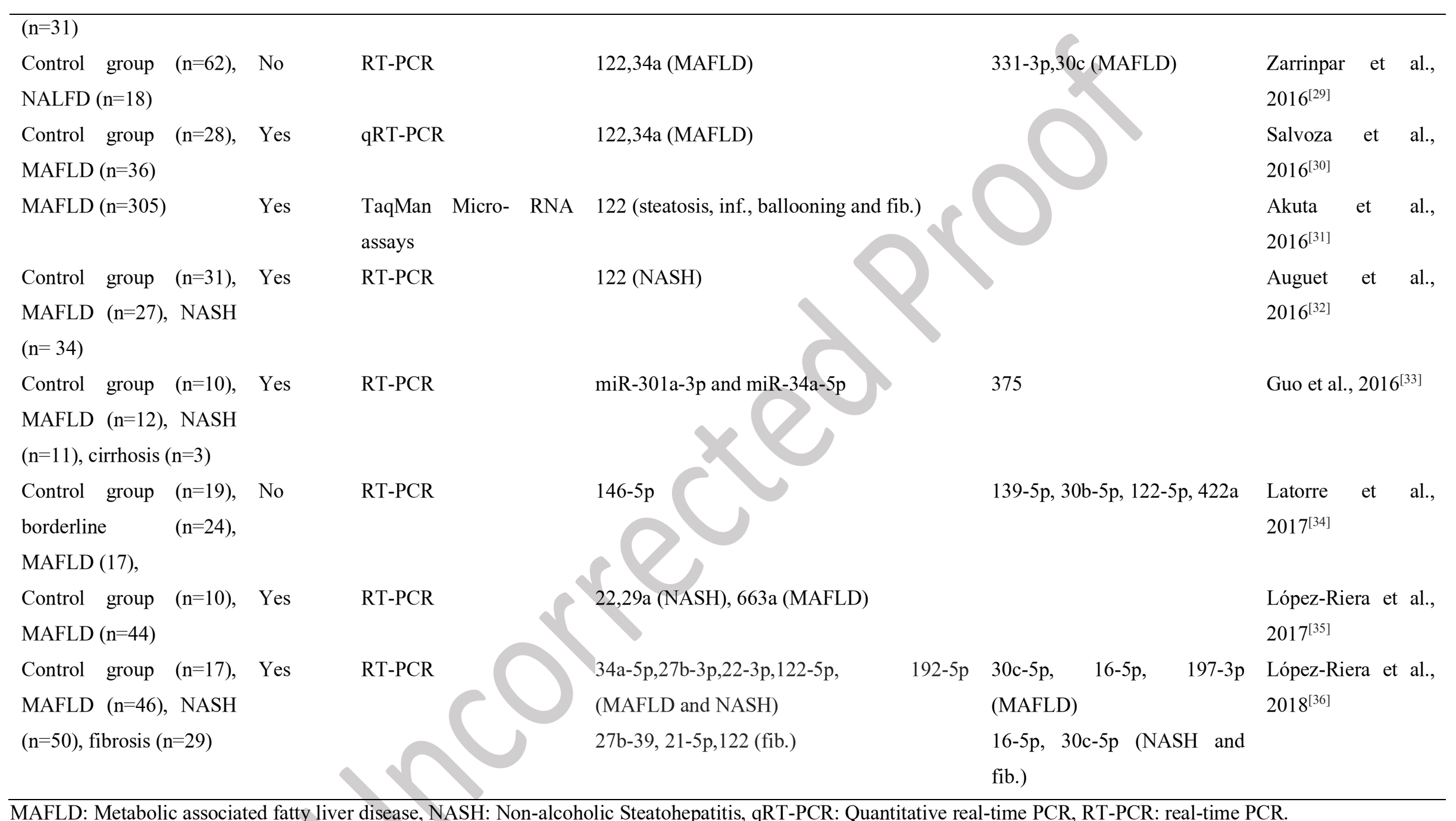

MAFLD: Metabolic associated fatty liver disease, NASH: Non-alcoholic Steatohepatitis, qRT-PCR: Quantitative real-time PCR, RT-PCR: real-time PCR. 
Table 2. Possible pathways of miRNAs in MAFLD

\begin{tabular}{|c|c|}
\hline miRNA & Pathway \\
\hline $\operatorname{miRNA}-122^{[61-64]}$ & Lipid metabolism (Cholesterol, VLDL, TG, HMGCR), carcinogenesis \\
\hline miRNA $-10 b^{[65]}$ & Lipid metabolism (PPAR- ) \\
\hline $\operatorname{miRNA}-33^{[66-68]}$ & ABC-A1 transport, ABC-G1, Niemann Pick (NP) -C1, insulin signal pathwa \\
\hline miRNA $-34^{[6,21,61,69-71]}$ & AMPK phosphorylation, miR-34a/SIRT1/p53 activation, MAFLD progression, lipid metabolism \\
\hline miRNA $-192^{[72,73]}$ & MAFLD progression \\
\hline $\operatorname{miRNA}-214-5 p^{[74]}$ & MAFLD progression \\
\hline miRNA $-27 \mathrm{a} / \mathrm{b}^{[75]}$ & Lipid metabolism \\
\hline miRNA $-24^{[76]}$ & Lipid metabolism (Insig1) \\
\hline miRNA $-451^{[77]}$ & Inflammation \\
\hline miRNA -1290, miRNA -27b- & Variable \\
\hline $3 \mathrm{p}^{[78]}$ & \\
\hline miRNA -192-5p $p^{[79]}$ & Lipid metabolism (Stearoyl-CoA desaturase 1 (SCD-1)) \\
\hline miRNA $-103 / 107^{[8,80,81]}$ & Pantothenate kinase 1-3 (PANK1-3), Lipid metabolism, development of insulin resistance, PPAR- , Caveolin-1 \\
\hline $\operatorname{miRNA}-155^{[82,83]}$ & Inflammation and liver injury, SREBP-lc, liver X Receptor R $\quad$ (LXR ) - lipid metabolism \\
\hline
\end{tabular}


miRNA -29[61]

\section{SIRT1, HMGCR, LPL}

$\operatorname{miRNA}-467 b^{[84]}$

LDL metabolism

miRNA $-143^{[85]}$

Fatty acid-binding protein 4 (FABP4), glucose transporter 4 (SLC2A4), peroxisome proliferator-activated receptor (PPAR ) and hormone-sensitive lipase (LIPE)

HMGCR: HMG-CoA reductase, VLDL: very-low-density lipoprotein, TG: triglycerides, PPAR- : Peroxisome proliferator-activated receptor-alpha, ABCA1: member 1 of human transporter sub-family ABCA, ABC-G1: ATP-binding cassette sub-family G member 1, NP-C1: Niemann Pick-C1, HDL: High-Density Lipoprotein, AMPK: AMP-activated protein kinase, SIRT-1: Sirtuin-1, SCD-1: Stearoyl-CoA desaturase 1, PANK1-3: Pantothenate kinase 1-3, SREBP-lc: Sterol regulatory element-binding transcription factor 1, LXR : liver X Receptor R , LPL: Lipoprotein lipase, LDL: Low-Density Lipoprotein, FABP4: Fatty acid-binding protein 4, SLC2A4: Solute carrier family 2, facilitated glucose transporter member 4, PPAR : peroxisome proliferator-activated receptor , LIPE: hormone-sensitive lipase. 
Table 3. Summary of in vitro and in vivo studies

\begin{tabular}{|c|c|c|c|c|c|c|}
\hline Model & Design of the study & Polyphenols & Method & Upregulated miRNAs & Downregulated miRNAs & References \\
\hline In vitro & $\begin{array}{l}\text { Human hepG2 cells, } 3.125,6.25 \text {, } \\
12.5,25 \text { and } 50 \mathrm{~g} / \mathrm{ml}, 72 \mathrm{~h}\end{array}$ & Ellagitannins & qRT-PCR & $\begin{array}{l}\text { hsa-let-7e, hsa-miRNA- } \\
\text { 370,hsa-miRNA-373 and } \\
\text { hsa-miRNA-526b }\end{array}$ & $\begin{array}{l}\text { hsa-let-7a, hsa-let-7c and hsa- } \\
\text { let-7d }\end{array}$ & Wen et al., 2009[43] \\
\hline In vitro & $\begin{array}{l}\text { Human hepG } 2 \text { cells, } 50 \mathrm{mg} / \mathrm{L} \text { of } \\
\text { EGCG, } 100 \mathrm{mg} / \mathrm{L} \text { of } \mathrm{GSPE} \text { or } \\
100 \mathrm{mg} / \mathrm{L} \text { of CPE, } 5 \mathrm{~h}\end{array}$ & GSPE, CPE or EGCG & qRT-PCR & $\begin{array}{l}\text { miRNA-1224-3p, miR-197 } \\
\text { and miR-532-3p (GSPE or } \\
\text { CPE) }\end{array}$ & $\begin{array}{l}\text { miRNA-30b (GSPE, CPE, } \\
\text { EGCG) }\end{array}$ & $\begin{array}{l}\text { Arola-Arnal et al., } \\
2011^{[15]}\end{array}$ \\
\hline In vitro & $\begin{array}{l}\text { 3T3-L1 maturing pre-adipocytes, } \\
25 \mathrm{M}, 8 \text { days }\end{array}$ & Resveratrol & RT-PCR & & & $\begin{array}{l}\text { Eseberri et al., } \\
2017^{[45]}\end{array}$ \\
\hline In vitro & $\begin{array}{l}\text { Human pre-adipocytes, } 25 \\
\mathrm{~mol} / \mathrm{L}, 6 \mathrm{~h}\end{array}$ & $\begin{array}{l}\text { The Extra-Virgin Olive Oil } \\
\text { polyphenols }\end{array}$ & qPCR & & miRNA-155, miRNA-34a & Carpi et al., 2019 ${ }^{[47]}$ \\
\hline $\begin{array}{l}\text { In vitro } \\
\text { In vitro }\end{array}$ & $\begin{array}{l}\text { FAO cells, } 25 \mathrm{mg} / \mathrm{L} \text { for } 5 \mathrm{~h} \\
\text { Male Wistar rats, } 250 \mathrm{mg} / \mathrm{kg}, 3 \mathrm{~h}\end{array}$ & GSP & qRT-PCR & & miRNA-122, miRNA-33 & $\begin{array}{l}\text { Baselga-Escudero et } \\
\text { al., 2012 }\end{array}$ \\
\hline In vitro & $\begin{array}{l}\text { Human hepG2 cells, 0.02, 0.2, } 2 \\
\text { and } 20 \mathrm{~g} / \mathrm{mL}, 24 \mathrm{~h}\end{array}$ & EGCG & & $\begin{array}{l}\text { miRNA-221, miRNA-181 } \\
\text { miRNA-10b }\end{array}$ & & $\begin{array}{l}\text { Arffra et al., } \\
2016^{[44]}\end{array}$ \\
\hline In vivo & $\begin{array}{l}\text { Male Sprague Dawley rats, } \\
20 \mathrm{mg} / \mathrm{kg}, 16 \text { weeks }\end{array}$ & Green tea & & & & \\
\hline In vitro & $\begin{array}{l}\text { 3T3-L1 maturing pre-adipocytes, } \\
25 \mathrm{M}, 24 \mathrm{~h}\end{array}$ & Curcumin & RT-PCR & miRNA-17-5p & & Tian et al., 2017 ${ }^{[46]}$ \\
\hline In vivo & $\begin{array}{l}\text { Male C57BL/6 mice, 2-10 M, } 7 \\
\text { days }\end{array}$ & & & & & \\
\hline In vivo & $\begin{array}{l}\text { Male } \mathrm{C} 57 \mathrm{BL} / 6 \mathrm{~J} \text { mice, } 0.5 \text { to } \\
1.0 \% \mathrm{CPP}, 15 \text { weeks }\end{array}$ & Coffee polyphenols & RT-PCR & miRNA-122 & & $\begin{array}{l}\text { Murase et al., } \\
2011^{[50]}\end{array}$ \\
\hline In vivo & $\begin{array}{l}\text { Female C57BL } / 6 \mathrm{~J} \text { mice, } 0,0.2 \text { or } \\
2 \mathrm{mg} / \mathrm{g}, 6 \text { weeks }\end{array}$ & Quercetin & RT-PCR & miRNA-122 miRNA-125b & & $\begin{array}{l}\text { Boesch- } \\
\text { Saadatmandi et al., }\end{array}$ \\
\hline
\end{tabular}




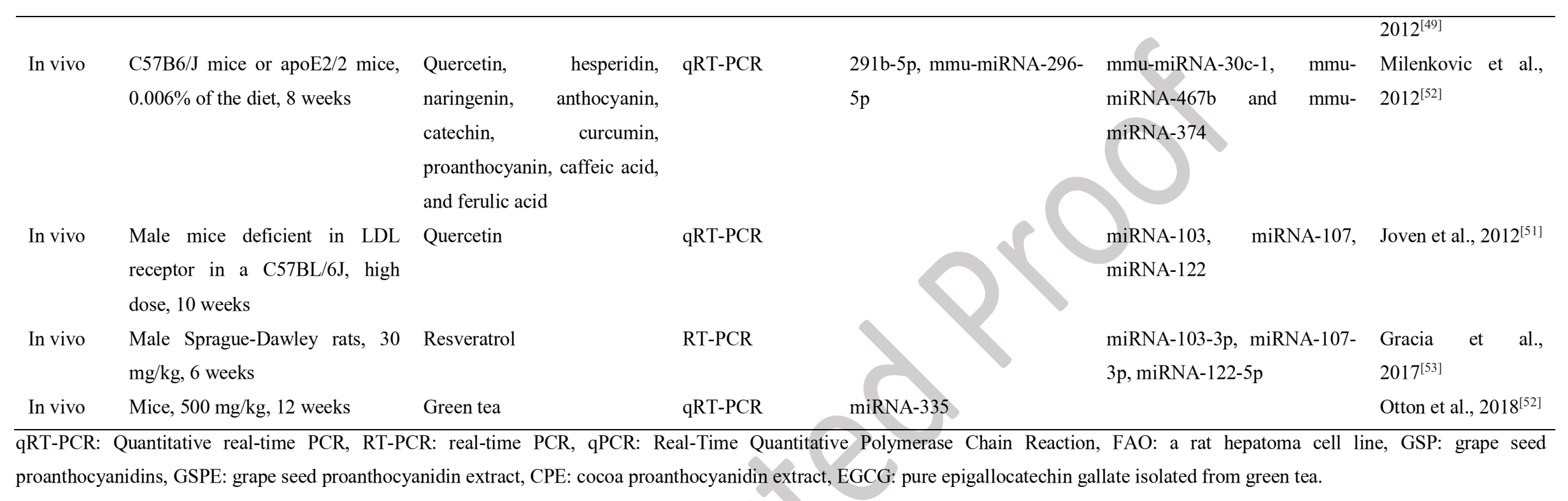




\section{Figure legends}

Figure 1. The implication of miRNAs in key transitions of the pathogenesis of nonalcoholic fatty liver disease

Figure 2. Possible effects of polyphenols on MAFLD-associated miRNAs 